\title{
Russian Mortality Crisis and the Quality of Vital Statistics
}

\author{
Natalia S. Gavrilova • Victoria G. Semyonova • \\ Elena Dubrovina - Galina N. Evdokushkina • \\ Alla E. Ivanova · Leonid A. Gavrilov
}

Received: 21 August 2006/Accepted: 24 June 2007/Published online: 29 May 2008

(C) Springer Science+Business Media B.V. 2008

\begin{abstract}
Mortality from ill-defined conditions in Russia has the fastest rate of increase compared to all other major causes of death. High proportion of deaths in this category is indicative for low quality of mortality statistics. This article examines the trends and possible causes of mortality from ill-defined conditions in Russia. During 1991-2005, mortality from ill-defined conditions in Russia increased in all age groups. The pace of increase was particularly high at working ages and the mean expected age at death from ill-defined conditions has shifted to younger ages, particularly for men. The analysis of individual medical death certificates issued in Kirov and Smolensk regions of Russia demonstrate that $89-100 \%$ of working-age deaths from ill-defined conditions correspond to human bodies found in a state of decomposition. Data from Smolensk region shows that over $60 \%$ of these decedents were unemployed. Temporal trends of mortality from ill-defined conditions and injuries of undetermined intent in Moscow city suggest that deaths from the latter cause were probably misclassified as ill-defined conditions. This practice can lead to underestimation of mortality from external causes. Growing number of socially isolated marginalized people in Russia and insufficient investigation of the circumstances of their death contribute to the observed trends in mortality from ill-defined conditions.
\end{abstract}

\footnotetext{
N. S. Gavrilova $(\bowtie) \cdot$ L. A. Gavrilov

Center on Demography and Economics of Aging, NORC at the University of Chicago,

1155 East 60th Street, Chicago, IL 60637, USA

e-mail: nsgavril@uchicago.edu

V. G. Semyonova · G. N. Evdokushkina · A. E. Ivanova

Central Research Public Health Institute at the Russian Ministry of Health, Moscow, Russia

E. Dubrovina

Kirov Department of Health Statistical Office, Kirov, Russia
} 
Keywords Russia · Ill-defined conditions · Injuries · Data quality ·

Vital statistics · Mortality

\section{Introduction}

The dramatic social, political and economic changes that have happened in Russia during the 1990s are well documented (Ellman 1994; Rose 2000; Shkolnikov et al. 1998a; Walberg et al. 1998). In 1992 and 1998 Russia experienced two serious economic crises accompanied with drop in personal income and rapid impoverishment (Gavrilova et al. 2000; Shkolnikov et al. 1998a). In both cases, adverse economic changes were followed by mortality increase. From 1992 to 1994, the life expectancy of Russian males dropped from 63.8 to 57.7 years. Female life expectancy dropped from 74.4 to 71.2 years. After 1995, all-cause mortality in Russia demonstrated a slow but stable decrease indicating partial recovery. However, in August 1998 Russia experienced another economic crisis resulting in mass impoverishment (Gavrilova et al. 2000; Shkolnikov et al. 1998a). Shortly after this crisis, mortality increased again and after 2000 stabilized at high level. In 2005 life expectancy in Russia was equal to 58.6 years for males and 71.8 years for females. During both crises population at working age was the most vulnerable age group, while children and the elderly were not significantly affected (Notzon et al. 1998). The observed decline in life expectancy is beyond the peacetime experience of any industrialized country. Life expectancy of Russian males is now lower than in many developing countries (Table 1).

Russian mortality crisis received significant attention in the scientific literature (Brainerd and Cutler 2005; Ellman 1994; Gavrilova et al. 1997; Notzon et al. 1998; Shkolnikov et al. 1995a, b, 1998a, 2004; Tulchinsky and Varavikova 1996; Walberg et al. 1998). These studies showed that diseases of the circulatory system and injuries were the major causes of death contributing to the decrease in life expectancy in Russia after 1991.

Table 1 Life expectancy at birth in Russia and other countries

\begin{tabular}{llll}
\hline Country & Year & \multicolumn{2}{l}{ Life expectancy at birth } \\
\cline { 4 - 4 } & & Men & Women \\
\hline Russia & 1991 & 63.1 & 73.5 \\
& 1994 & 57.3 & 70.6 \\
& 2001 & 58.7 & 71.6 \\
& 2003 & 58.4 & 71.4 \\
Libya & 2005 & 58.6 & 71.8 \\
Bangladesh & $2000-2005$ & 67.5 & 71.0 \\
Brazil & $2000-2005$ & 60.4 & 60.8 \\
United States & $2000-2005$ & 64.5 & 71.9 \\
\hline
\end{tabular}

Source: Goskomstat Russia (Russia), World Health Organization (other countries) 
Although previous studies provided an important information on the magnitude and causes of mortality increase, little attention was paid to the causes of death with the highest rate of growth-the so-called "unspecified" or "ill-defined" causes of death. It seems unlikely that this growth is a consequence of an increased accuracy of diagnostics. Most likely, this phenomenon is an indicator of decline in the level of diagnostics and deterioration of data quality (Gavrilova et al. 2000; Semyonova et al. 2004a, b). We believe that the problem of data quality in Russian mortality statistics should receive more attention, and the aim of this study is to increase understanding about the scale and possible causes of this problem.

As indicators of data quality we used (1) death rates attributed to category "Symptoms, signs and ill-defined conditions" according to the 9th revision of the International Classification of Diseases (ICD-9) or "Symptoms, signs and abnormal clinical and laboratory findings, not elsewhere classified" according to the 10th revision of the same classification (here and thereafter this category is called "ill-defined conditions"), and (2) death rates attributed to "injuries undetermined whether accidentally or purposely inflicted" (codes E980-E989 according to ICD-9) or causes comprising the section Y10-Y34 ("Event of undetermined intent") of ICD-10. This cause of death is a part of external mortality and is used for coding deaths with unknown manner of death.

The proportion of deaths assigned to ill-defined conditions is used by WHO experts for evaluation of quality of death data (Mathers et al. 2005). The percentage of ill-defined codes higher than $10 \%$ indicates medium data quality. If this percentage is higher than $20 \%$ then quality of death data is considered to be low (Mathers et al. 2005). The second cause of death (injuries of undetermined intent) was used as an additional indicator of death data quality. There is an opinion that many injuries of undetermined intent represent hidden homicides (Gavrilova et al. 2005; Pridemore 2003; Sorenson et al. 1997a; Wasserman and Varnik 1998).

\section{Data and Methods}

This study is based on mortality data from the official Russian statistics. For better understanding of possible factors affecting the quality of mortality statistics, we describe here the process of death registration in Russia. This is particularly important because of changes in death registration procedure taken place after the last publications on this topic (Andreev et al. 1995; Shkolnikov et al. 1995b).

\section{Registration of death in the Russian Federation}

According to the law of the Russian Federation of 11/15/97, death is subject to official state registration. State registration is conducted by regional Registries of Acts of Civil Status (Zapis' aktov grazhdanskogo sostoyaniya) commonly referred as ZAGS. Registration of death in ZAGS is based on the official document issued by a medical organization (hospital) or private physician when a person dies. This official document (called "medical death certificate") is brought (or submitted) to ZAGS office by relatives/friends of the decedent or by state officers for the official 
death registration. A death certificate is needed before the dead could be buried. ZAGS death certificate is a legal document certifying the fact of death, which is given to relatives or friends of the decedents in exchange of the medical death certificate. In the majority of cases, state registration of death is conducted by ZAGS offices located in the decedent's last place of residence, place of body finding, or location of organization that issued medical death certificate.

ZAGS death certificate contains the following information about the decedent: name, age, sex, place of residence and cause of death. Statisticians report only one principal cause of death on ZAGS death certificate. ZAGS death certificates are collected by regional branches of the state statistics (Goskomstat Rossii) and submitted to the central office of Goskomstat in Moscow. ZAGS death certificates are then aggregated by sex, age group and type of residence (urban/rural) producing official statistical forms C51 for every large region of Russia (oblast, national republic) and for Russia itself. Information available in C51 forms is used for further analyses and official publications including regular issues of the statistical yearbooks of Russia (Goskomstat 2001).

Medical organizations and physicians use two official documents for death registration established by the Russian Ministry of Health: medical death certificate and medical certificate for perinatal death (when death occurred during the first week of life). Medical death certificate is issued by a medical organization regardless of its property form or by private physician. This document consists of two parts: the first part is handed to the spouse or other relatives after obtaining their signature on the second part of the document. The second copy of the document is retained in the medical organization or in the office of private physician. These second copies of death certificates are used for analytical and statistical purposes by local health agencies. If medical organization conducts the burial, then medical death certificate should be submitted to the local ZAGS within 3-day period for state registration.

Medical death certificate is issued with one of the following checkmarks: "final", "pending" or "replaces pending." These rules were adopted in order to ensure reliability of registered causes of death and for avoiding delays in death registration at local ZAGS offices. Medical death certificate with checkmark "pending" is issued in those cases when an additional investigation is needed in order to establish the true cause of death or when the manner of external death (accident, suicide, homicide) was not known by the time of death registration but may be specified later. A new medical death certificate should be issued with a checkmark "replaces pending" and sent directly to the local statistical office no later than one month after a more correct cause of death is specified.

An official medical death certificate in Russia contains 19 items. These items include name of the deceased, his/her sex, dates of birth and death, place of permanent residence, place of death, place of death occurrence (hospital, home, other), cause of death (immediate cause, pathological conditions leading to the immediate cause, underlying cause, injury). It is important to note that some items in the medical death certificate (decedent's ethnicity, occupation, education, marital status) being mandatory in the past became optional according to the federal law adopted in 1997. As a result of this law, many death certificates issued after 1997 have no information on a social status of decedent. 
Starting with 1999, all medical organizations and private physicians in Russia are required to report underlying cause of death according to the 10th revision of the International Classification of Diseases (WHO 1992). As in all countries reporting to WHO, three levels of cause of death can be registered on the Russian death certificate: underlying, immediate, and associated (contributory) cause of death. Comparison of ZAGS and medical death certificates in the Udmurt Republic of Russia showed very little disagreement in terms of the ICD classes of causes of death (Shkolnikov and Chervyakov 2000). Unfortunately the practice of multiplecause coding of deaths has been lost during the past decade. Most physicians now do not pay attention to multiple causes of deaths and report only one cause of death on medical death certificates (Vaysman et al. 2006).

Item 14 of death certificate indicates the manner of death (disease, accident, homicide, etc.) after establishing circumstances of particular death case. If it is impossible to determine the manner of death an option "manner of death could not be determined" is checked. In the case of external death, medical examiner should report a particular manner of death (accident, suicide, homicide). Item 15 indicates date of injury (poisoning) in all cases of deaths due to injury or poisoning. Then follows information on place where injury occurred and circumstances of injury. In all cases of deaths due to injury or poisoning, two codes are filled out: direct cause of death due to injury or poisoning according to its type (19th class of ICD-10) and an external cause of death (20th class of ICD-10).

\section{Data Sources}

Age and sex-specific death counts by cause (form C51) and population counts were used for mortality analyses. Goskomstat of Russia uses its own classification of causes of death in C51 forms. In 1986-1998 this classification contained 185 causes of death, which roughly corresponded to the 9th revision of ICD. Some causes of death in this classification differed from the international classification (particularly causes in a group of cardiovascular diseases). In 1999 the list of causes of death reported on the $\mathrm{C} 51$ forms was extended to 251 causes making this classification closer to the international standards (10th revision of ICD).

We used medical death certificates for deaths occurred in 2003 in three regions of Russia (Kirov oblast, Smolensk oblast and Moscow city). Data were obtained from the regional Departments of Health in each corresponding region (oblast). For Kirov and Smolensk regions, we analyzed all deaths attributed to symptoms, signs and abnormal clinical and laboratory findings, not elsewhere classified (400 death certificates for Kirov oblast and 149 certificates for working-age persons in Smolensk oblast). For Moscow city, we used a sample of death certificates for 6,513 men and 1,560 women who died at working ages (20-59) from external causes. These numbers correspond to $96.7 \%$ and $96.5 \%$, respectively, of all deaths from external causes registered in 2003 in Moscow city.

Both Kirov and Smolensk regions are located in the European part of Russia (Fig. 1) and have predominantly urban population: $72.4 \%$ and $70.7 \%$ respectively (Rosstat 2006). In 2004, working population of Kirov and Smolensk regions have 


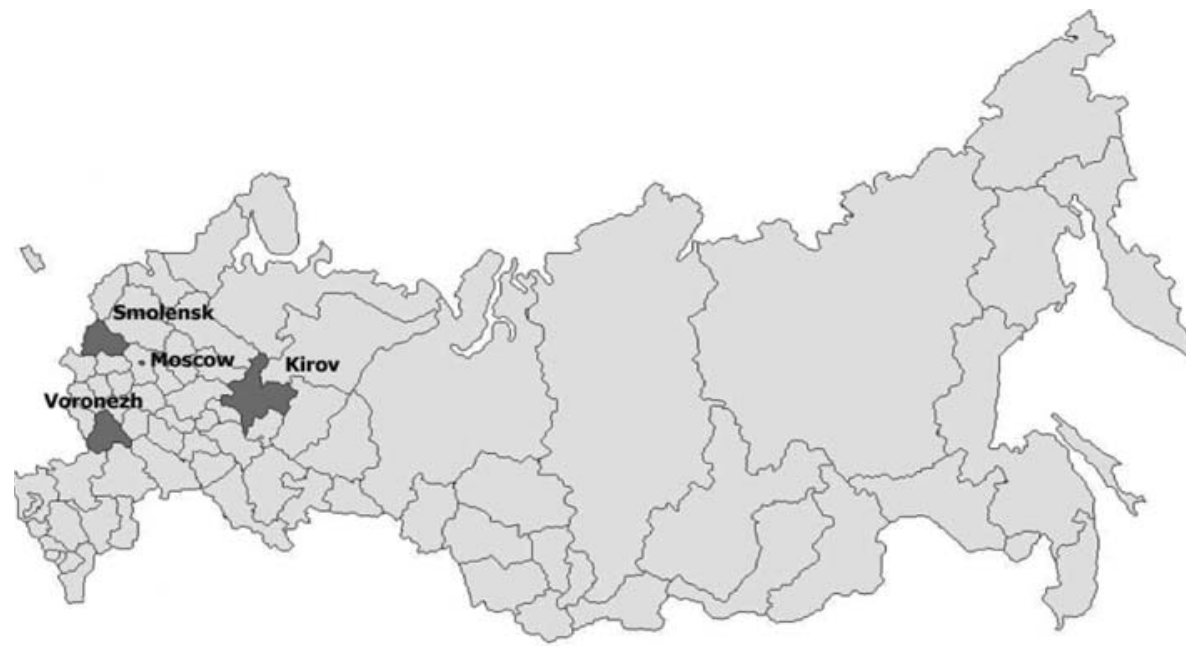

Fig. 1 Map of Russia indicating geographical positions of Kirov, Smolensk and Voronezh regions

monthly earnings lower than the national average while monthly earnings of Moscow population significantly exceeded the national level (Rosstat 2006).

Life expectancy in Kirov (63.9 years) and Smolensk (62.3 years) regions is lower than the national level (65.3 years in 2004). Population of Moscow city has higher life expectancy at birth compared to Russia-70.8 years in 2004. Mortality from external causes in both Kirov and Smolensk regions exceeds the Russian average. Kirov region is characterized by low mortality from ill-defined conditions $(1.6 \%$ of all deaths and $2.9 \%$ of deaths at working age), indicating a good quality of mortality statistics. Smolensk region has relatively low mortality from ill-defined conditions at working age (2.4\% of deaths at working age and $4.8 \%$ of all deaths). Moscow city, on the contrary, has rather high proportion of deaths from ill-defined conditions (5.2\% of all deaths and $13.6 \%$ of deaths at working age). Before 2000, Moscow city ranked among the leading regions of Russia for mortality from injuries of undetermined intent. Thus, these regions represent territories with different quality of death statistics (high quality in Kirov, medium quality in Smolensk and low quality in Moscow city).

\section{Methods}

Age-adjusted death rates were calculated by the direct method and standardized to the 2000 US standard million population (Chiang 1978). Life expectancy for selected years (Table 1) was calculated using the iterative method of life table construction (Keyfitz 1966). Mean expected age at death was calculated using a method of multiple decrement life tables (Preston et al. 2001). Deaths of unknown age (less than 7\%) were distributed over age groups using the observed age distribution of death counts. 


\section{Russian Mortality Statistics: Previous Studies of Data Quality}

The rapid and drastic changes in mortality experienced by Russia in the recent decades have raised concerns about the quality of Russian vital statistics (Anderson and Silver 1997). Most authors working with Russian mortality data came to a conclusion that recent mortality fluctuations in Russia are not artifactual and that population estimates and death counts are accurate enough to ensure correct statistical analyses (Andreev et al. 1995; Leon et al. 1997; Notzon et al. 1998; Wasserman and Varnik 1998). One of the arguments supporting the acceptable quality of Russian statistics is temporal stability of cancer mortality in 1992-1995 against the background of a dramatic increase in total mortality (Leon et al. 1997). Wasserman and Varnik (1998) conducted a study of the reliability of statistics on violent death and suicide in the republics of the former USSR. They concluded that the Soviet mortality data were reliable for Russia, Ukraine, and Belarus.

The completeness of death reporting in Russia is considered to be rather high except for the North Caucasus Republics and the Republic of Tyva (Andreev et al. 1995). Recent estimates of mortality at middle ages using the indirect widowhood method demonstrated a good agreement with the official mortality data (Bobak et al. 2002). However a high level of death registration in some regions does not exclude poor death coverage in other parts of Russia. For example, information on deaths in Chechnya was not collected from 1994 to 2002. According to WHO, the overall level of completeness for mortality data in Russia is 100\% (Mathers et al. 2005).

Despite generally acceptable level of mortality completeness, the quality of cause-of-death coding is not always good (Andreev et al. 1995; Notzon et al. 1998). The last audit of the accuracy in reporting causes of death was conducted in Russia in 1982 (Shkolnikov et al. 1995b, 1997). Shkolnikov et al. (1995b) describe the results of several audits of death registration in Russia before 1983. It is interesting that these audits did not reveal overdiagnostics of cardiovascular deaths despite a widespread opinion to the contrary.

Most researchers studying the problem of data quality in Russia focus their attention on possible misreporting of alcohol-related deaths as cardiac deaths. This possibility is supported by indirect evidence showing high mortality from cardiovascular diseases during weekends-a period of excessive alcohol consumption in Russia (Chenet et al. 1998b). Recent study of death certificates by medical experts in the city of Izhevsk (Russia) did not find a support for suggestion that cardiac deaths at middle ages mask deaths from alcohol intoxication (Shkolnikov et al. 2002). At the same time, this study demonstrated that over $60 \%$ of male decedents in the sample had alcohol in blood when died. Thus, there is a possibility that many cardiac deaths, particularly at working ages, are alcohol related (even if alcohol was not a cause of a lethal intoxication).

Although overdiagnostics of cardiac deaths at middle ages can somewhat affect the quality of mortality statistics, registration of deaths from violent causes raises particular concerns (Gavrilova et al. 2000, 2005). The main problem here is an unprecedented increase of mortality from injuries of undetermined intent during the last decade (Russian code 175, new code 251 in C51 form). Some researchers 
believe that this code could be used to conceal deaths due to homicide or suicide in order to avoid criminal investigation (Pridemore 2003; Wasserman and Varnik 1998). Male mortality from this cause increased dramatically after 1992 reaching its maximum in 1994. It was found that in Moscow, with its relatively high proportion of unregistered migrants, homeless, and refugees, male mortality from injuries of undetermined intent exceeded any other cause of external mortality in 1994 (Gavrilova et al. 2000, 2001). With all these limitations, mortality statistics is better source of information about homicide victimization rates in Russia compared to other existing sources (Gavrilova et al. 2005; Pridemore 2003). For example, crime statistics based on police reports underreports homicide rates compared to vital statistics in the majority of Russian regions (Pridemore 2003).

Thus, while population estimates and death counts are reasonably accurate in Russia, the quality of death coding is less satisfactory. This limitation can bias the estimates of mortality from external causes leading to underestimation for some causes of death (especially for homicide and suicide deaths which may be reassigned to "injuries of undetermined intent" or ill-defined conditions). Despite the increasing number of deaths from nonspecified causes in Russia research on this phenomenon has yet to be undertaken. This study aims to increase understanding about the trends and possible causes of mortality from ill-defined conditions.

\section{What is Concealed Behind the Unspecified Causes of Death?}

Ill-defined conditions represent the fastest growing cause of death in Russia (see Fig. 2).

Between 1991 and 2005, age-adjusted mortality from ill-defined conditions increased 2.0 times for males and 1.7 times for females whereas mortality from all causes increased by $21.8 \%$ and $13.1 \%$ respectively, mortality from cardiovascular

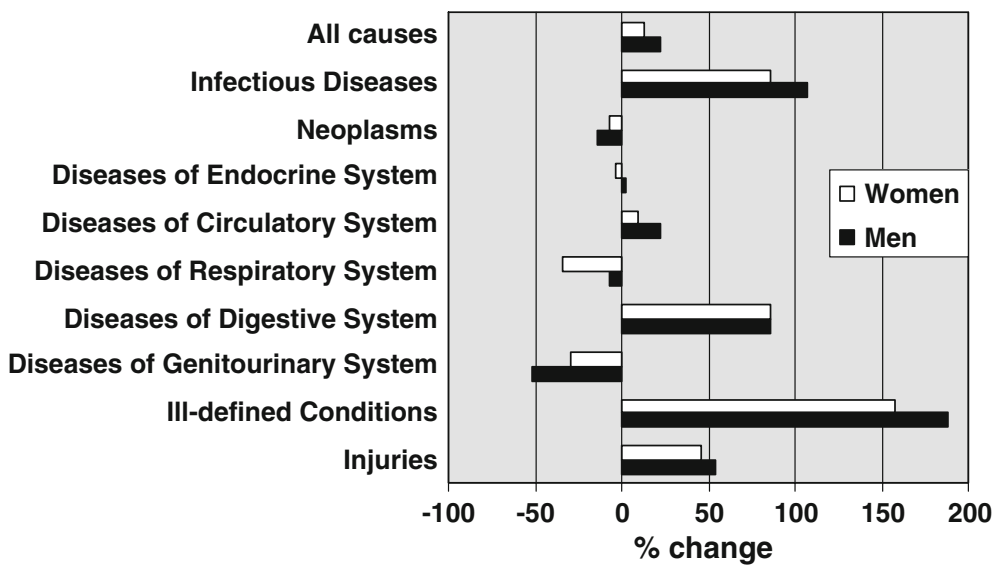

Fig. 2 Percent change in age-adjusted death rates for major cause groups: 1991-2005, Russian Federation 
diseases by $23.8 \%$ and $12.5 \%$ and mortality from external causes of death by $44.8 \%$ and $40.1 \%$ (Fig. 2). In 2005 ill-defined conditions was the 5th leading cause of death for males and the 4th leading cause of death for females in Russia.

What is the reason of such rapid growth of mortality from unknown causes? Indeed, according to the description of unspecified causes in ICD-10, "this chapter includes symptoms, signs, abnormal results of clinical or other investigative procedures, and ill-defined conditions regarding which no diagnosis classifiable elsewhere is recorded" (WHO 1992). There is an opinion that ill-defined conditions may mask a part of mortality from cardiovascular diseases at older ages, because the current classification includes "senility" (R54). This opinion is supported by the instructions of the USSR Ministry of Health, which were issued in 1989 (Shkolnikov et al. 1995b). These instructions advised medical workers to refrain from overdiagnostics of heart diseases for older decedents (unless the diagnosis is established by autopsy) and to use a code for "senility" instead. This resulted in skyrocketing mortality from ill-defined conditions between 1989 and 1991. Some researchers considered these changes as an improvement of data quality at that time (Mesle 2002). During 1991-2005, the death rate from ill-defined conditions increased 2.2 times for older men and 1.6 times for older women over age 60.

If mortality from ill-defined conditions increased in the 1990s due to changes in coding that were introduced in 1989 , then one might expect a stability of death rates from ill-defined conditions for younger age groups. To explore this issue further, we studied mortality at younger ages when "senility" is not a likely diagnosis. We found that mortality from ill-defined conditions increased in all age groups below 60 years (Table 2).

During 1991-2005, mortality of infants from ill-defined conditions increased two-fold (1.9 times for boys and 2.1 times for girls), whereas the infant mortality from all causes declined $13.8 \%$ and $10.4 \%$ respectively, during the same period; mortality of children aged 1-14 increased 2.5 times and 2.4 times (whereas mortality from all causes decreased $10.8 \%$ and $5.9 \%$ ); mortality of adolescents aged 15-19 years increased 4.3 and 2.6 times whereas mortality from all causes increased $38 \%$ and $24 \%$ respectively. Mortality from ill-defined conditions for working-age population (20-59) increased 4.6 times for males and four times for females whereas mortality from all causes increased $59.7 \%$ and $43.4 \%$ respectively. In fact, working ages showed the fastest increase in mortality from ill-defined conditions compared to other age groups. This growth has led to substantial changes in the pattern of working-age mortality, particularly at young adult ages (15-39 years). In this age group, the proportion of deaths from ill-defined conditions increased from $2.1 \%$ in 1991 to $5.9 \%$ in 2003 for men and from $2.0 \%$ to $4.9 \%$ for women; the rank of this cause of death for young adults shifted from the 6-10th place in 1991 to the $3-5$ th place in 2003, and ill-defined conditions became one of the leading causes of death for young adults in Russia.

This analysis shows that mortality from ill-defined conditions increased in all age groups of the Russian population and ill-defined conditions has had the steepest increase in death rates compared to other major causes of death. During 1991-2005, deaths from ill-defined conditions shifted to younger ages. This conclusion is supported by the analysis of mean expected age at death. This demographic 
Table 2 Mortality attributed to ill-defined conditions by age and sex, Russia, 1991-2005

\begin{tabular}{lrrrrrrrr}
\hline Year & 1991 & \multicolumn{1}{c}{1993} & \multicolumn{1}{c}{1995} & 1997 & 1999 & 2001 & 2003 & 2005 \\
\hline Men & & & & & & & & \\
Age & & & & & & & & \\
$<1$ & 47.67 & 59.96 & 61.93 & 65.96 & 87.43 & 75.28 & 71.05 & 77.54 \\
$1-14$ & 1.12 & 1.60 & 1.45 & 1.57 & 2.02 & 2.73 & 2.43 & 2.59 \\
$15-19$ & 2.58 & 4.48 & 6.24 & 5.19 & 7.18 & 8.06 & 7.40 & 7.46 \\
$20-59$ & 14.77 & 33.64 & 39.68 & 28.44 & 39.41 & 60.87 & 69.49 & 71.33 \\
$60+$ & 116.27 & 204.64 & 229.49 & 204.58 & 198.62 & 229.75 & 259.44 & 251.64 \\
Women & & & & & & & & \\
Age & & & & & & & & \\
$<1$ & 34.11 & 47.09 & 47.3 & 55.42 & 63.83 & 62.93 & 59.60 & 61.57 \\
$1-14$ & 0.79 & 1.10 & 1.10 & 0.98 & 1.42 & 1.76 & 1.60 & 1.83 \\
$15-19$ & 1.75 & 1.65 & 2.46 & 2.24 & 3.19 & 3.53 & 3.06 & 2.96 \\
$20-59$ & 3.59 & 7.72 & 9.04 & 6.83 & 8.83 & 13.46 & 15.43 & 15.89 \\
$60+$ & 175.48 & 283.85 & 327.82 & 336.68 & 317.60 & 295.84 & 304.22 & 287.63 \\
\hline
\end{tabular}

a Age-specific death rates per 100,000 population

indicator is derived from the multiple decrement life tables and is not dependent on the age structure of population. We found that mean expected age at death from illdefined conditions decreased from 70.0 and 82.0 years in 1991 to 56.1 and 78.6 years in 2005 for men and women respectively. After 1998 the decline of mean expected age at death from ill-defined condition was particularly rapid: 11.2 years for males and 3.4 years for females. Figures 3 and 4 show that between 1991 and 2005 mortality from both ill-defined conditions and injuries increased predominantly in a group of working-age men and women.

These observations suggest that ill-defined conditions may mask not only cardiovascular mortality, but external causes of death as well.

We hypothesize that many cases of external deaths in Russia are concealed now under the mask of ill-defined conditions. This suggestion is supported by the composition of causes comprising the class "Symptoms, signs and abnormal clinical and laboratory findings not elsewhere classified" of ICD-10, such as "Instantaneous death" (R960) "Unattended death" (R98), "Other sudden death, cause unknown" (R96) and "Other ill-defined and unspecified causes of mortality" (R99). Taking into account the realities of Russia with its high rate of violent crime (Chervyakov et al. 2002; Gavrilova et al. 2005; Pridemore 2002) and growing income inequality (Bobak et al. 1998), these causes of death may be indicative of deaths due to injuries, particularly at young adult age groups, in which the level of mortality is determined by external causes.

To test this hypothesis, we analyzed 400 medical death certificates from the Kirov region in order to understand what specific causes are included in the class "ill-defined conditions." We found that overwhelming majority of cases that fall into this group is represented by decomposed bodies found in various places (Table 3). 

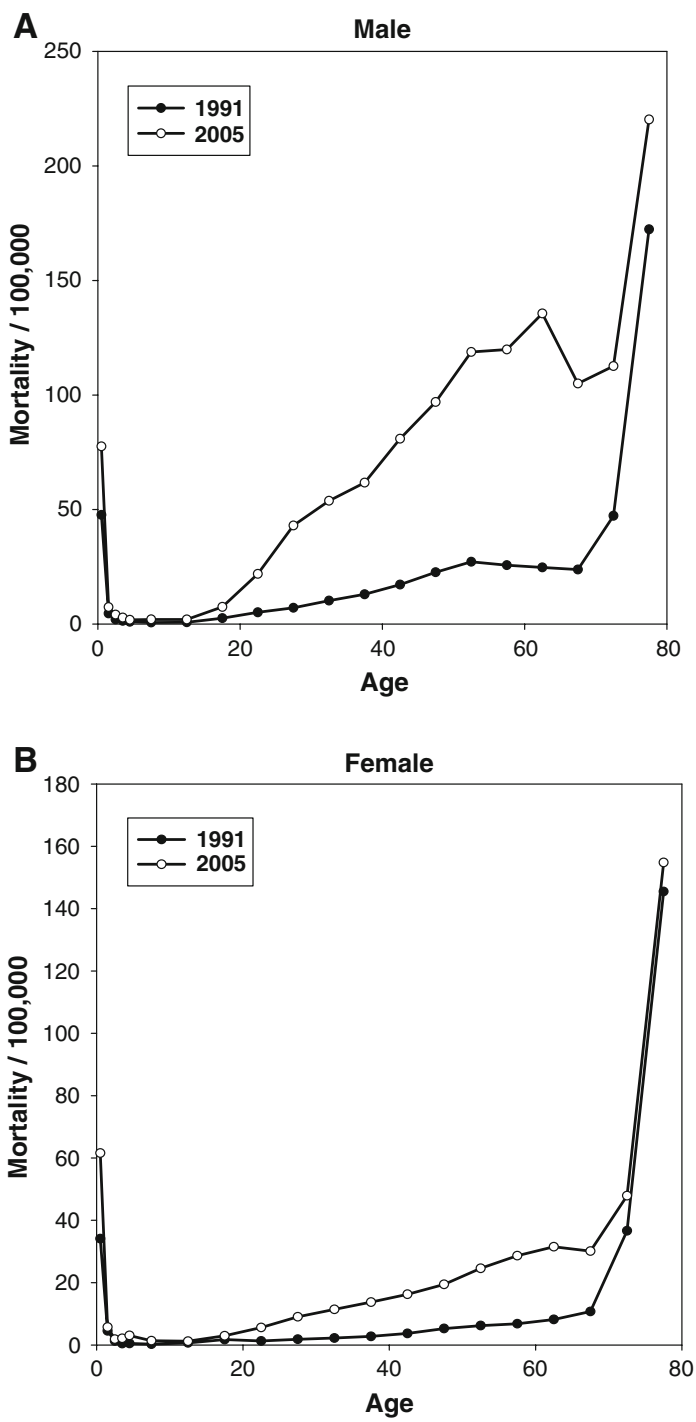

Fig. 3 Age profile of mortality from ill-defined conditions in 1991 and 2001; (a) Males; (b) Females

Although part of these deaths might be explained by sudden cardiac deaths (particularly when human bodies were found at home), other cases raise concern about possible external (and perhaps even violent) causes of death. For example, bodies found in water (10\% of all cases), water pipe or vegetable storage pit most likely represent external deaths. At all ages, males have significantly higher external mortality rate than females, so it is indicative that over half of male bodies $(56 \%)$ were found outside home compared to only $37 \%$ of female bodies. Note that almost $94 \%$ of all deaths attributed to ill-defined conditions and $100 \%$ of these deaths at working ages were coded using ICD-10 code R99 and all such cases corresponded 

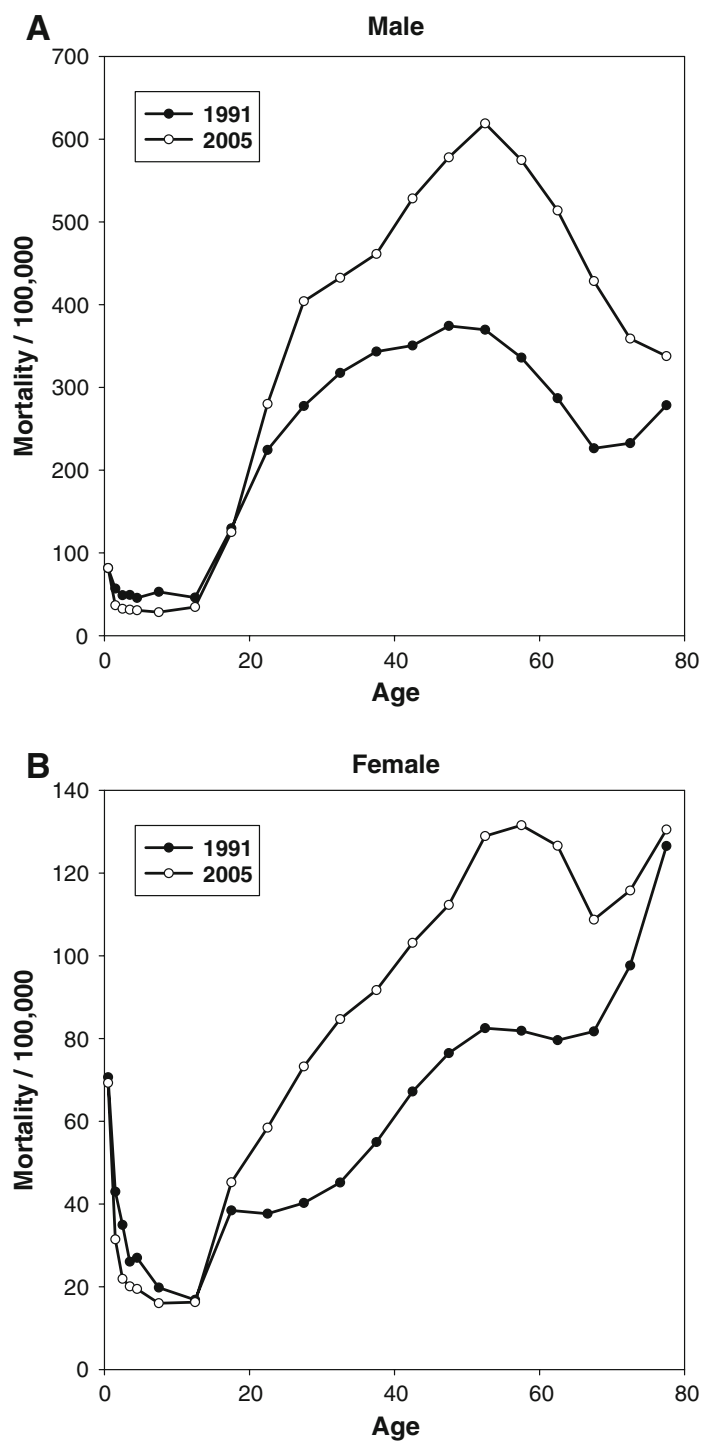

Fig. 4 Age profile of mortality from external causes of death in 1991 and 2001; (a) Males; (b) Females

to decomposed bodies. It would be reasonable to assume that the percentage of deaths from external causes would be the same among deaths due to ill-defined conditions and total deaths. External causes comprise about $35 \%$ of total deaths for working-age males and about $25 \%$ of total deaths for working-age females in Russia. Thus, we may estimate that in Kirov region about 70 out of 201 working-age male deaths and 10 out of 38 working-age female deaths coded as ill-defined conditions, represent deaths from external causes. These conservative estimates are slightly lower than the numbers of decomposed bodies found outside home (108 and 14 for working-age males and females respectively). It should be noted that the 
Table 3 Age and sex distribution of deaths (absolute numbers) from ill-defined conditions. Kirov oblast of Russia, 2003

\begin{tabular}{llllllll}
\hline Detailed description of death from & \multicolumn{3}{l}{ Age group } \\
\cline { 2 - 6 } medical death certificate & $<1$ year & $1-$ & $15-$ & $20-$ & $40-$ & $60+$ & Total \\
& & 14 & 19 & 39 & 59 & \\
\hline
\end{tabular}

\section{Men}

Sudden infant death (R95)

Decomposition in water (river, well, pond) (R99)

Decomposition at home (R99)

Decomposition in garden, summer house (R99)

Decomposition in forest (R99)

Decomposition in field (R99)

Decomposition in nonresidential building (R99)

Decomposition on the street (R99)

Decomposition in water pipe (R99)

Decomposition on the cemetery (R99)

Decomposition in bath, lavatory or barn (R99)

Decomposition in other place (R99)

Unknown (R99)

Senility (R54)

Total

Women

Sudden infant death (R95)

Decomposition in forest (R99)

Decomposition on the street (R99)

Decomposition at home (R99)

Decomposition in water (river, well, pond) (R99)

Decomposition in nonresidential building (R99)

Decomposition in vegetable storage pit (R99)

Decomposition in field (R99)

Decomposition in garden, summer house (R99)

Decomposition in other place (R99)

Unknown (R99)

\begin{tabular}{|c|c|c|c|c|c|}
\hline 1 & 2 & 15 & 21 & & 39 \\
\hline & & 11 & 82 & 68 & 161 \\
\hline & & & 5 & & 5 \\
\hline & & 3 & 5 & 4 & 12 \\
\hline & & 2 & 2 & 2 & 6 \\
\hline & & 2 & 5 & 3 & 10 \\
\hline & & 5 & 20 & 2 & 27 \\
\hline & & & 2 & & 2 \\
\hline & & & 1 & & 1 \\
\hline & & & 2 & 1 & 3 \\
\hline & 1 & 4 & 10 & 2 & 17 \\
\hline & & & 4 & 3 & 7 \\
\hline & & & & 1 & 1 \\
\hline 10 & 3 & 42 & 159 & 86 & 301 \\
\hline 3 & & & & & 3 \\
\hline & & & 3 & 3 & 6 \\
\hline & & & 3 & 2 & 5 \\
\hline & & 3 & 21 & 28 & 52 \\
\hline & & & 1 & & 1 \\
\hline & & & 1 & & 1 \\
\hline & & & 1 & & 1 \\
\hline & & & & 3 & 3 \\
\hline & & & 3 & & 3 \\
\hline & & 1 & & 1 & 2 \\
\hline & & & 1 & 10 & 11 \\
\hline & & & & 11 & 11 \\
\hline 3 & & 4 & 34 & 62 & 99 \\
\hline
\end{tabular}

Senility (R54)

Total

Kirov region has rather low mortality from ill-defined conditions compared to other parts of Russia. We may conclude that the observed increase of mortality from illdefined conditions in the Kirov region is most likely caused by growing number of bodies found in a state of decomposition (reflecting the realities of life in contemporary Russia). 
A total of 149 medical death certificates issued in 2003 in the Smolensk region allowed us to analyze social characteristics of men and women died from ill-defined conditions. ICD code R99 was assigned to $88.6 \%$ of death certificates and all these cases corresponded to decomposed bodies. We analyzed all 132 death certificates of working-age persons whose bodies were found in a state of decomposition. Among $82 \%$ males and $23 \%$ females, $65 \%$ were not married, $62 \%$ were unemployed and $45 \%$ had lower than secondary education. This information suggests low level of social interactions (with relatives or colleagues at work) among persons died from unspecified causes (code R99). Absence of relatives and/or friends was probably the main reason of finding body in a state of decomposition. Lack of relatives and other interested persons is the most likely reason why these cases of death were not properly investigated. This suggestion is supported by data on mortality of non-residents in Moscow city. It was found that non-residents (who have less social interactions compared to residents) are responsible for unexpectedly high proportion of deaths assigned to ill-defined conditions in Moscow city in 2003 (Arhangelsky et al. 2006).

If deaths from external causes are miscoded as ill-defined conditions more often now than in the past, we may expect a tendency of increasing proportion of deaths from ill-defined conditions and decreasing proportion of external deaths in total deaths. We tested this hypothesis for deaths of working population in Russia. The results presented in Table 4 confirm this suggestion: during 1991-2005, contribution of deaths from ill-defined conditions to total deaths increased and contribution of external deaths to total deaths decreased among the Russian working-age population.

Thus, we may suggest that the growth of mortality from nonspecified causes at working age is accompanied by substitution of deaths coded as injuries with deaths coded as ill-defined conditions. What causes of external deaths are more likely to be misclassified as ill-defined conditions in Russia? Partial answer to this question is suggested in the next section.

\section{Ill-Defined Conditions and Injuries of Undetermined Intent as Two Sides of the Same Coin}

The problem of data quality becomes even more explicit when we analyze external mortality. The group of external mortality in ICD-10 contains a section Y10-Y34, "Event of undetermined intent." According to ICD-10, "this section covers events where available information is insufficient to enable a medical or legal authority to make a distinction between accident, self-harm and assault. It includes self-inflicted injuries, but not poisoning, when not specified whether accidental or with intent to harm" (WHO 1992). In 2005, injuries of undetermined intent occupied the second position among the external causes of death for Russian males (after suicide) whereas in 1991 this cause of external mortality occupied only the 5th position. During 19912005, the age-adjusted death rate from injuries of undetermined intent increased 2.4 times for males and 2.2 times for females, whereas the external mortality increased only $44.8 \%$ for males and $40.1 \%$ for females. In 2005 , injuries of undetermined intent were responsible for $15.5 \%$ of male deaths and $14.3 \%$ of female deaths from external causes compared to less than $2 \%$ in the United States (Sorenson et al. 1997b). 
Table 4 Trends in numbers and proportions of deaths from ill-defined conditions and injuries for working-age men and women in Russia

\begin{tabular}{|c|c|c|c|c|}
\hline \multirow[t]{2}{*}{ Cause of death } & \multicolumn{2}{|l|}{ Men } & \multicolumn{2}{|l|}{ Women } \\
\hline & $\begin{array}{l}\text { Number } \\
\text { of deaths }\end{array}$ & $\begin{array}{l}\text { Proportion }(\%) \\
\text { of total deaths }\end{array}$ & $\begin{array}{l}\text { Number } \\
\text { of deaths }\end{array}$ & $\begin{array}{l}\text { Proportion (\%) } \\
\text { of total deaths }\end{array}$ \\
\hline \multicolumn{5}{|c|}{ Ill-defined conditions } \\
\hline 1990 & 12,249 & 3.80 & 1,345 & 1.17 \\
\hline 1991 & 15,688 & 4.74 & 1,463 & 1.25 \\
\hline 1992 & 20,960 & 5.42 & 1,880 & 1.45 \\
\hline 1993 & 30,969 & 6.23 & 3,152 & 1.95 \\
\hline 1994 & 36,894 & 6.48 & 3,848 & 2.08 \\
\hline 1995 & 35,661 & 6.59 & 3,733 & 2.11 \\
\hline 1996 & 32,122 & 6.67 & 3,049 & 1.91 \\
\hline 1997 & 29,906 & 6.99 & 2,820 & 1.93 \\
\hline 1998 & 29,170 & 7.08 & 2,643 & 1.90 \\
\hline 1999 & 35,067 & 7.71 & 3,625 & 2.42 \\
\hline 2000 & 43,087 & 8.74 & 4,782 & 3.05 \\
\hline 2001 & 46,811 & 9.29 & 5,523 & 3.39 \\
\hline 2002 & 47,636 & 9.05 & 5,706 & 3.30 \\
\hline 2003 & 52,375 & 9.43 & 6,581 & 3.53 \\
\hline 2004 & 50,691 & 8.99 & 6,550 & 3.43 \\
\hline 2005 & 51,390 & 8.83 & 6,995 & 3.51 \\
\hline \multicolumn{5}{|l|}{ Injuries } \\
\hline 1990 & 117,852 & 36.57 & 22,814 & 19.92 \\
\hline 1991 & 125,794 & 37.99 & 24,131 & 20.67 \\
\hline 1992 & 157,203 & 40.66 & 30,580 & 23.64 \\
\hline 1993 & 205,386 & 41.32 & 42,802 & 26.44 \\
\hline 1994 & 225,999 & 39.66 & 47,681 & 25.80 \\
\hline 1995 & 212,848 & 39.33 & 44,773 & 25.35 \\
\hline 1996 & 186,404 & 38.70 & 39,089 & 24.46 \\
\hline 1997 & 163,809 & 38.27 & 34,750 & 23.81 \\
\hline 1998 & 162,894 & 39.54 & 34,192 & 24.59 \\
\hline 1999 & 177,874 & 39.10 & 37,584 & 25.09 \\
\hline 2000 & 191,233 & 38.81 & 39,603 & 25.25 \\
\hline 2001 & 196,525 & 38.99 & 41,701 & 25.59 \\
\hline 2002 & 199,569 & 37.91 & 44,069 & 25.47 \\
\hline 2003 & 199,971 & 36.02 & 44,929 & 24.10 \\
\hline 2004 & 198,578 & 35.23 & 44,644 & 23.39 \\
\hline 2005 & 194,772 & 33.47 & 42,903 & 21.53 \\
\hline
\end{tabular}

What real causes of death are hidden behind the injuries of undetermined intent-homicides, suicides or accidents? The answer to this question may be partially given by the analysis of regional mortality. During the 1990s, two regions had the highest levels of mortality from injuries of undetermined intent: Voronezh 
region and the Moscow city (see map at Fig. 1). At the same time, Voronezh region had the lowest level of homicide mortality in Russia. The level of homicide mortality in Voronezh region was even lower than the rate of murders reported by police crime statistics (Pridemore 2003). Police crime statistics in the majority of Russian regions reported on average 20 percent lower rate of murders compared to mortality statistics (Pridemore 2003) suggesting underreporting of homicides by mortality statistics in Voronezh region. Assuming that the quality of Voronezh police statistics does not differ from other Russian regions in the level of completeness, we may estimate that the real rate of homicide mortality in Voronezh region is at least $20 \%$ higher than the level reported by the vital statistics.

Voronezh region is notorious not only for high mortality from injuries of undetermined intent but also for the highest level of mortality from ill-defined conditions in Russia. For example in 2005, mortality from ill-defined conditions exceeded the national level 2.6 and 4.5 times for Voronezh males and females respectively. In 2005 ill-defined conditions in this region had the second rank among the leading causes of death after cardiovascular diseases. Situation with data quality is particularly troublesome for young adult ages (15-39 years) where more than $25 \%$ of deaths is coded as ill-defined conditions suggesting very poor quality of vital statistics according to the WHO criteria (Mathers et al. 2005). The case of Voronezh region demonstrates that homicides may be misreported as injuries of undetermined intent.

Moscow city is an example of territory where external deaths in mortality statistics were almost explicitly replaced with deaths from ill-defined conditions. In the 1990s, Moscow city occupied one of the leading positions according to the reported level of mortality from injuries of undetermined intent. This cause of death was among the leading causes of external mortality for Moscow city. However this situation has changed over one-year period. In 2000, the reported crude mortality from injuries of undetermined intent has suddenly decreased 2.2 times both for males and females and the Russian capital was no longer among the leaders for this kind of mortality. More detailed analysis of this phenomenon found that during the same year (2000) mortality structure in Moscow city has underwent significant changes and the notorious ill-defined conditions moved from the 12-13th to the 6th position. Mortality from ill-defined conditions of children and the elderly was subjected to minimal changes while mortality of 1-14 aged boys and 15-19 aged girls moved from the 13th to the 5th and from the 17th to the 2nd position respectively. These striking changes resulted in 8-fold increase of male mortality and 6-fold increase of female mortality from ill-defined conditions. It is interesting that combined mortality rate from ill-defined conditions and injuries of undetermined intent has remained virtually the same (141.29 in 1998 and 122.35 in 2003 per 100,000 on the background of 9 -fold increase in mortality from ill-defined conditions). Figure 5 illustrates this paradoxical phenomenon.

As a result, external mortality in Moscow dropped by $28.6 \%$ for young males and by $31.8 \%$ for young females (aged 20-39) in one year, from 1999 to 2000. This example demonstrates that injuries of undetermined intent can be easily replaced with ill-defined conditions in an official statistics.

In order to understand what kind of injuries are attributed to injuries of undetermined intent, we examined notes on 1,201 death certificates issued in 


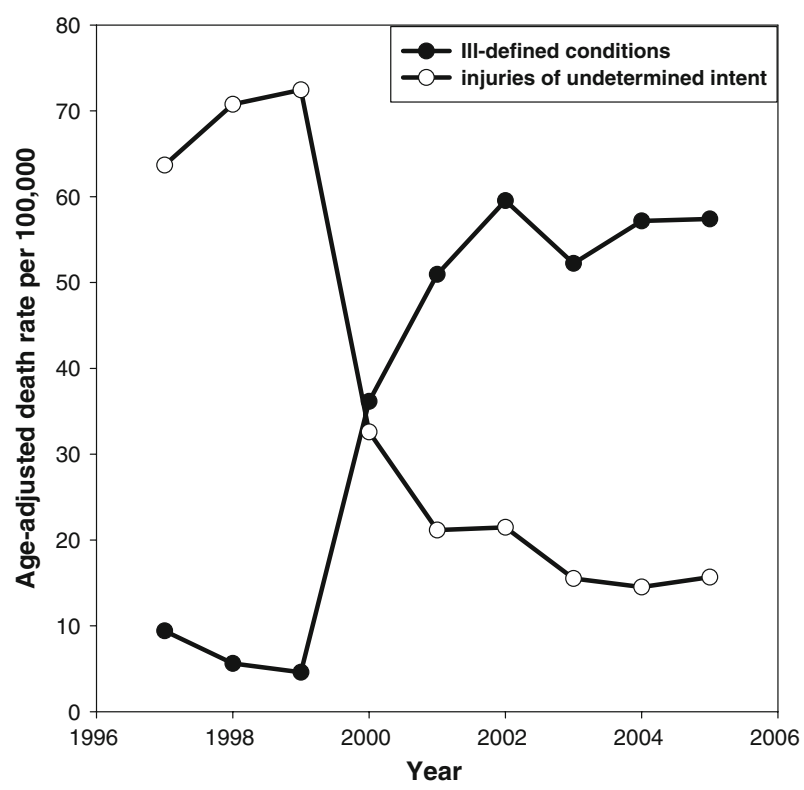

Fig. 5 Age-adjusted death rates (per 100,000) from injuries of undetermined intent and ill-defined conditions in Moscow city, 1997-2005

Moscow city in 2003. Discussing the accuracy of death certificates issued for cases of external death we need to take into account that an official statistics should use information available in three items of medical death certificate: (1) clinical description of death (anatomical localization and type of injury), (2) information about external cause of death-accident (related or unrelated to industry), homicide, suicide or unknown manner of death (item 14 of medical death certificate) and (3) code of underlying cause of death according to ICD-10. In the case of external death there should be two codes: the first one should reflect a clinical picture of death and the second one - a manner of death and its external cause.

According to ICD-10, injuries of undetermined intent (Y10-Y34) include cases where information is not sufficient for medical and legal experts to make a decision about the manner of death. In our case, 75 out of 1,201 death certificates $(6.2 \%)$ had no code of injury by its type and localization and 33 death certificates had no clinical description of death. Further analysis of notes in item 18 revealed that out of 1201 cases 39 were consequences of fire, 28 were homicides, 22 represented traffic accidents, 7 were suicides and 7 were results of firearm injuries. In 30 cases the death occurred as a result of a contact with sharp and in 229 cases with blunt object (Table 5).

Recent studies using data from other regions of Russia suggest that such cases ("contact with blunt object") would be more reasonable to code as homicide interpreting homicide as the act of killing another human being, leaving the question of intent to the legal organs (Semyonova et al. 2004a). 


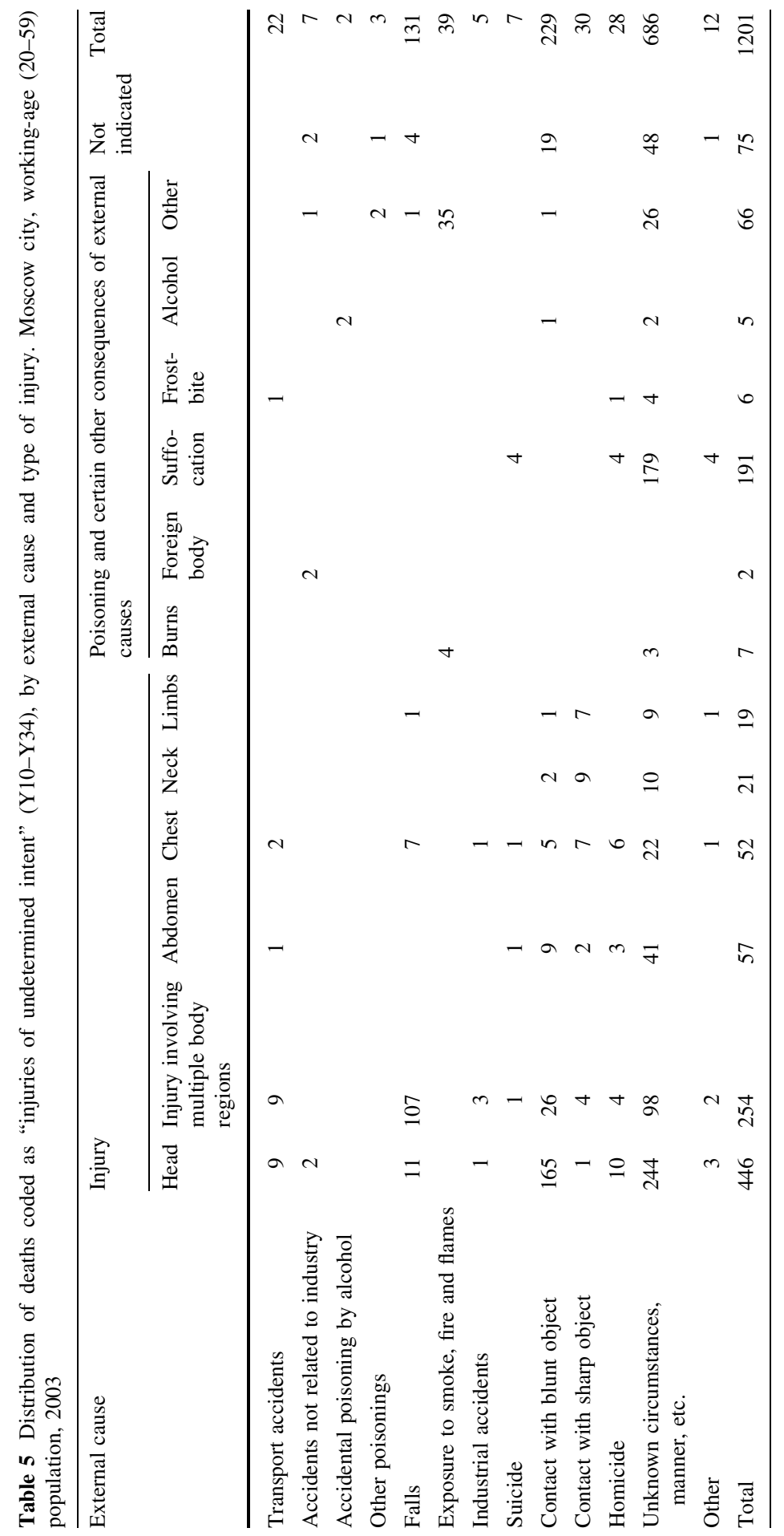


A total of 686 death certificates $(57.1 \%)$ contained notes "Manner of death not specified, circumstances not reported," although in 179 cases death was caused by hanging (Table 5). Note that hanging is very common method of suicide in Russia (Gilinsky and Rumyantseva 2004) and probably "unknown intent" of such deaths is the main reason of very low suicide mortality in the Russian capital. However, in 507 cases there was no any information about clinical picture, circumstances or manner of death. Typically these cases were described as "accident not related to industry, circumstances not reported." Analysis of these injuries by their localization (48.1\% head, $19.3 \%$ multiple, $8.1 \%$ abdominal and $4.3 \%$ chest) showed a good resemblance with distribution of injuries received from a contact with blunt object. Thus, it is likely that many deaths among these 507 cases of unspecified injuries resulted from a contact with blunt object. Taking into account that a contact with blunt object is highly unlikely method of suicide (Gilinsky and Rumyantseva 2004) we may suggest that at least half of such cases (or $31 \%$ of all injuries of undetermined intent) may represent hidden homicides.

There is an opinion that undetermined injuries is a convenient place to classify cause unknown violent deaths when resources are insufficient to carry out a full investigation. This cause of death also may be used for purposeful misclassification of true homicides in order to reduce the number reported (Pridemore 2003). It was shown that regional ZAGS agencies often underreport homicide deaths when compared to the initial forensic medical records (Porodenko and Chernobai 1999). Such phenomenon is observed not only in Russia. For example, a study of infant and toddler deaths in the United States found that about $44 \%$ of the undetermined injury deaths were similar to homicides on several characteristics of dead child, injury event, and postmortem (Sorenson et al. 1997a). The analysis of Moscow workingage deaths found a similar proportion of deaths resembling homicides by characteristics of injury. These results suggest that the level of Russian homicide mortality which is already 30 times higher than in the European Union (Gavrilova et al. 2005) could still be underestimated, particularly for men. Also the external deaths with no information about circumstances, manner and clinical pattern are probably the most likely candidates to be misreported as ill-defined conditions.

\section{Discussion}

During 1991-2005, mortality from ill-defined conditions in Russia increased in all age groups. The pace of increase was particularly high at working ages and the mean expected age at death from ill-defined conditions has shifted to younger ages, particularly for men. The shift of deaths to younger ages suggests that many external deaths at working ages may be misreported as deaths from ill-defined conditions.

The steady growth of deaths attributed to ill-defined conditions in Russia could be due to several factors:

(1) the existing practice of preliminary (pending) and final death certificates. Preliminary death certificates are issued as a result of the provision made for sudden and violent deaths whose registrations are frequently delayed due to lengthy processes sometimes associated with the completion of the medical expertise and 
the supporting document needed for complete registration. Such delays are normally due to legal procedures. In reality, causes of death reported on preliminary death certificates often are not replaced by the final ones. In addition to that, the recent instructions of the Russian Ministry of Health (issued in 2003) facilitated the usage of nonspecific codes on final death certificates. According to these instructions, "inability to establish a manner of death is not a reason for issuing a pending death certificate; in this case, an option 'manner of death is not established' should be selected. " (Vaysman et al. 2006). These instructions encouraged registrants to use nonspecific codes in those cases of death that require an additional investigation.

(2) Growing number of human bodies found in a state of decomposition. As was demonstrated for the Kirov region, these bodies have been "discovered" in various places (home, river, garage, water pipe, etc.). This factor is particularly important for regions having relatively low mortality from ill-defined conditions (and hence better quality of mortality statistics). In regions with moderate or low quality of vital statistics (like Moscow city) many cases of external deaths of marginalized people are poorly investigated and contribute to the growing number of deaths from illdefined conditions.

(3) Statistical manipulations. The majority of death certificates with underlying cause of death coded with "R99" ICD-10 code come from medical examiners whose duty is to determine the time, cause, and manner of external death (Vaysman et al. 2006). This suggests a considerable external component in mortality from illdefined conditions. Temporal trends of mortality from ill-defined conditions and injuries of undetermined intent in Moscow city suggest that deaths from the injuries of undetermined intent are most likely misreported as ill-defined conditions.

All listed factors affect mortality statistics in all Russian regions although contribution of each factor in each region may vary.

Growth of mortality from ill-defined conditions during the 1990 s needs to be considered in a broader socio-economic context. First, this period was accompanied by rapid impoverishment of a considerable part of the Russian population. Disintegration of the Soviet Union in 1991 and subsequent economic changes resulted in growing social disorganization, poverty and violence, which contributed to already high levels of mortality in Russia (Chen et al. 1996; Plavinski et al. 2003; Pridemore and Shkolnikov 2004; Rose 2000; Shkolnikov et al. 1998a, b; Walberg et al. 1998). Social deregulation and increased alcohol consumption during the transition period resulted in growing crime rate and homicide rate in particular (Chervyakov et al. 2002; Gavrilova et al. 2005; Pridemore 2002; Walberg et al. 1998). Socially disadapted and low educated groups of Russian population were affected particularly hard (Chenet et al. 1998a; Pridemore 2004; Shkolnikov et al. 1998a; Shkolnikov and Chervyakov 2000). Deaths of marginal groups of population usually receive less attention from the official services including forensic services and police (Gavrilova et al. 2005). These socio-economic developments resulted in qualitative changes in the pattern of Russian mortality, which may be summarized as "marginalization" of Russian mortality (Ivanova et al. 2004). The main characteristics of this pattern are: degradation of the quality of a reported cause of death structure (more deaths are reported as "ill-defined" or "nonspecified"); misrepresentation of real mortality pattern (underestimation of external and violent 
deaths); development of a specific social portrait of a decedent at working age (unemployed and low educated man).

All these socio-economic changes affected the quality of mortality statistics and statistics of external mortality in particular. Underpaid police officers, overwhelmed with high number of criminal cases, often are reluctant to initiate criminal investigation when unidentified body is found (Chervyakov et al. 2002; Gavrilova et al. 2005; Pridemore 2002). This is particularly true for deaths of socially disadapted homeless persons. Even in the Former Soviet Union, with its significantly lower homicide rates, some cases of homicide were probably concealed under the mask of injuries of undetermined intent (Wasserman and Varnik 1998). It appears that in contemporary Russia a group of ill-defined conditions is often used for coding cases of external deaths. More detailed study of a social status of deceased (a case study of the Kirov region) shows a significant social differentiation of mortality patterns with unemployed individuals accounting for over half of all deaths at young working age (Ivanova et al. 2004). Thus, growing crime rate and proportion of socially disadapted individuals on one hand and low funding of police and forensic services on the other hand, resulted in declining quality of mortality statistics in Russia.

It should be admitted that the quality of Russian mortality statistics still conforms to the formal criteria developed by the World Health Organization and was considered to be "good" compared to the international standards (Mathers et al. 2005). The proportion of deaths from ill-defined conditions in Russia (4.74\%) is below the critical level of 5 percent indicating less than good data quality (Mathers et al. 2005). For comparison, in the United States the proportion of deaths coded as "ill-defined conditions" comprise only $1.34 \%$ of all deaths (data from the WHO mortality database). However, the pattern of deaths attributed to this category differs in Russia and the United States. In Russia, the proportion of deaths from ill-defined conditions is the highest at working ages whereas in the United States most deaths in this category occur in older people. More than $80 \%$ of deaths from ill-defined conditions in Russia are coded as R99 compared to only 55\% in the United States. Most deaths from ill-defined conditions in industrialized countries are related to poor diagnostics of chronic diseases. For example, high proportion of deaths from ill-defined conditions among the U.S. minorities compared to whites was caused by underreporting deaths from chronic diseases (Becker et al. 1990; Bridgers and Lehman 1977). In Russia, on the contrary, many deaths from ill-defined conditions are most likely related to external and perhaps event violent causes.

The death rate from ill-defined conditions accelerated in Russia during the last 57 years, especially among working-age males. If this tendency continues, the structure and pattern of Russian mortality and mortality from external causes in particular may be distorted.

Acknowledgments An earlier version of this paper was presented at the Annual Meeting of the Population Association of America, March 29-April 2, 2005, Philadelphia. This study was supported in part by the Center on Demography and Economics of Aging pilot grant \# P30 AG-12857-06 from the National Institute on Aging (NIA). We would like to thank two anonymous reviewers for their useful comments and suggestions on the topic of this article. 


\section{References}

Anderson, B. A., \& Silver, B. D. (1997). Issues of data quality in assessing mortality trends and levels in the New Independent States. In J. L. Bobadilla, C. A. Costello, \& F. Mitchell (Eds.), Premature death in the New Independent States (pp. 120-155). National Academy Press.

Andreev, E., Scherbov, S., \& Willekens, F. (1995). Sources of information on the population of Russia. University of Groningen Press.

Arhangelsky, V. N., Ivanova, A. E., Rybakovsky, L. L., \& Ryazantsev, S. V. (2006). Demographic situation in Moscow and tendencies of its development. [Demograficheskaya situatsiya v Moskve $\mathrm{i}$ Tendentsii ee razvitiya]. Center of Social Forecasting.

Becker, T. M., Wiggins, C. L., Key, C. R., \& Samet, J. M. (1990). Symptoms, signs, and ill-defined conditions: a leading cause of death among minorities. American Journal of Epidemiology, 131(4), 664-668.

Bobak, M., Murphy, M., Pikhart, H., Martikainen, P., Rose, R., \& Marmot, M. (2002). Mortality patterns in the Russian Federation: Indirect technique using widowhood data. Bulletin of the World Health Organization, 80(11), 876-881.

Bobak, M., Pikhart, H., Hertzman, C., Rose, R., \& Marmot, M. (1998). Socioeconomic factors, perceived control and self-reported health in Russia. A cross-sectional survey. Social Science \& Medicine, 47(2), 269-279.

Brainerd, E., \& Cutler, D. M. (2005). Autopsy on an empire: Understanding mortality in Russia and the former Soviet Union. Journal of Economic Perspectives, 19(1), 107-130.

Bridgers, W. F., \& Lehman, H. F. (1977). Mortality in Alabama attributed to symptoms and ill-defined conditions. Alabama Journal of Medical Sciences, 14(3), 297-302.

Chen, L. C., Wittgenstein, F., \& McKeon, E. (1996). The upsurge of mortality in Russia: Causes and policy implications. Population and Development Review, 22(3), 517-530.

Chenet, L., Leon, D., McKee, M., \& Vassin, S. (1998a). Deaths from alcohol and violence in Moscow: Socio-economic determinants. European Journal of Population-Revue Europeenne De Demographie, 14(1), 19-37.

Chenet, L., McKee, M., Leon, D., Shkolnikov, V., \& Vassin, S. (1998b). Alcohol and cardiovascular mortality in Moscow; new evidence of a causal association. Journal of Epidemiology and Community Health, 52(12), 772-774.

Chervyakov, V. V., Shkolnikov, V. M., Pridemore, W. A., \& McKee, M. (2002). The changing nature of murder in Russia. Social Science \& Medicine, 55(10), 1713-1724.

Chiang, C. L. (1978). Life table and mortality analysis. WHO.

Ellman, M. (1994). The increase in death and disease under Katastroika. Cambridge Journal of Economics, 18(4), 329-355.

Gavrilova, N. S., Evdokushkina, G. N., Ermakov, S. P., \& Gavrilov, L. A. (1997). An analysis of the health and mortality data for the provinces of Russia. In Proceedings of the International Population Conference, Beijing (pp. 1245-1257). IUSSP.

Gavrilova, N. S., Evdokushkina, G. N., Semyonova, V. G., \& Gavrilov, L. A. (2001). Economic crises, stress and mortality in Russia. In Population Association of America. 2001 Annual Meeting (pp. 220-221). PAA.

Gavrilova, N. S., Gavrilov, L. A., Semyonova, V. G., Evdokushkina, G. N., \& Ivanova, A. E. (2005). Patterns of violent crime in Russia. In W. A. Pridemore (Eds.), Ruling Russia: Law, crime, and justice in a changing society (pp. 117-145). Rowman \& Littlefield Publ., Inc.

Gavrilova, N. S., Semyonova, V. G., Evdokushkina, G. N., \& Gavrilov, L. A. (2000). The response of violent mortality to economic crisis in Russia. Population Research and Policy Review, 19(5), 397-419.

Gilinsky, Y., \& Rumyantseva, G. (2004). Main trends of suicide in Russia. Demoscope Weekly [Russian electronic edition], 161-162.

Goskomstat. (2001). Rossiyskiy Statisticheskiy Ezhegodnik. Russian Statistical Yearbook.

Ivanova, A. E., Semyonova, V. G., \& Dubrovina, E. (2004). Marginalization of Russian mortality. Demoscope Weekly [Russian electronic edition], 181-182.

Keyfitz, N. (1966). A life table that agrees with data. Journal of the American Statistical Association, 61(314P), 305-311.

Leon, D. A., Chenet, L., Shkolnikov, V. M., Zakharov, S., Shapiro, J., Rakhmanova, G., et al. (1997). Huge variation in Russian mortality rates 1984-94: Artefact, alcohol, or what? Lancet, 350(9075), 383-388. 
Mathers, C. D., Fat, D. M., Inoue, M., Rao, C., \& Lopez, A. D. (2005). Counting the dead and what they died from: an assessment of the global status of cause of death data. Bulletin of the World Health Organization, 83(3), 171-177.

Mesle, F. (2002). The registration of causes of death: Problems of comparability. In G. Wunsch, M. Mouchart, \& J. Duchene (Eds.), The life table. Modelling survival and death (pp. 171-190). Kluwer Academic Publishers.

Notzon, F. C., Komarov, Y. M., Ermakov, S. P., Sempos, C. T., Marks, J. S., \& Sempos, E. V. (1998). Causes of declining life expectancy in Russia. Journal of the American Medical Association, 279(10), 793-800.

Plavinski, S. L., Plavinskaya, S. I., \& Klimov, A. N. (2003). Social factors and increase in mortality in Russia in the 1990s: Prospective cohort study. British Medical Journal, 326(7401), 1240-1242.

Porodenko, V. A., \& Chernobai, V. V. (1999). Current trends in the dynamics of violent and nonviolent deaths and the problems in recording them. [Russian]. Sudebno Meditsinskaia Ekspertiza, 44(5), $20-23$.

Preston, S. H., Heuveline, P., \& Guillot, M. (2001). Demography. Measuring and modeling population processes. Blackwell Publishers.

Pridemore, W. A. (2002). Vodka and violence: Alcohol consumption and homicide rates in Russia. American Journal of Public Health, 92(12), 1921-1930.

Pridemore, W. A. (2003). Measuring homicide in Russia: A comparison of estimates from the crime and vital statistics reporting systems. Social Science \& Medicine, 57(8), 1343-1354.

Pridemore, W. A. (2004). Weekend effects on binge drinking and homicide: The social connection between alcohol and violence in Russia. Addiction, 99(8), 1034-1041.

Pridemore, W. A., \& Shkolnikov, V. M. (2004). Education and marriage as protective factors against homicide mortality: Methodological and substantive findings from Moscow. Journal of Quantitative Criminology, 20(2), 173-187.

Rose, R. (2000). How much does social capital add to individual health? A survey study of Russians. Social Science \& Medicine, 51(9), 1421-1435.

Rosstat. (2006). Regions of Russia. Socio-economic Indicators - 2005. Rosstat.

Semyonova, V. G., Dubrovina, E. V., Gavrilova, N. S., Evdokushkina, G. N., \& Gavrilov, L. A. (2004a). On the problems of trauma mortality in Russia: Kirov region case. [In Russian]. Obschestvennoe zdorovye i profilaktika zabolevaniy [Public Health and Disease Prevention], 3, 3-9.

Semyonova, V. G., Gavrilova, N. S., Evdokushkina, G. N., \& Gavrilov, L. A. (2004b). Data quality of medical statistics as a problem of modern Russian health care. [In Russian]. Obschestvennoe zdorovye i profilaktika zabolevaniy [Public Health and Disease Prevention], 2, 11-18.

Shkolnikov, V. M., Cornia, G. A. A., Leon, D. A., \& Mesle, F. (1998a). Causes of the Russian mortality crisis: Evidence and interpretations. World Development, 26(11), 1995-2011.

Shkolnikov, V. M., Leon, D. A., Adamets, S., Andreev, E., \& Deev, A. (1998b). Educational level and adult mortality in Russia: An analysis of routine data 1979 to 1994. Social Science \& Medicine, 47(3), 357-369.

Shkolnikov, V. M., McKee, M., Chervyakov, V. V., \& Kyrianov, N. A. (2002). Is the link between alcohol and cardiovascular death among young Russian men attributable to misclassification of acute alcohol intoxication? Evidence from the city of Izhevsk. Journal of Epidemiology and Community Health, 56(3), 171-174.

Shkolnikov, V., Mesle, F., \& Vallin, J. (1995a). Health crisis in Russia.1. Recent trends in life expectancy and causes of deaths from 1970 to 1993. Population, 50(4-5), 907-943.

Shkolnikov, V., Mesle, F., \& Vallin, J. (1995b). Health crisis in Russia.2. Changes in causes of deaths-A comparison with France and England and Wales from 1970 to 1993. Population, 50(4-5), 945-982.

Shkolnikov, V., Mesle, F., \& Vallin, J. (1997). Recent trends in life expectancy and causes of death in Russia, 1970-1993. In J. L. Bobadilla, C. A. Costello, \& F. Mitchell (Eds.), Premature death in the new independent states (pp. 34-65). National Academy Press.

Shkolnikov, V. M., Andreev, E. M., Leon, D. A., McKee, M., Mesle, F., \& Vallin, J. (2004). Mortality reversal in Russia: The story so far. Hygiea Internationalis, 4(4), 29-80.

Shkolnikov, V. M., \& Chervyakov, V. V. (2000). Policies for the control of the transition's mortality crisis in Russia. United Nations Development Programme (UNDP)/Transnational Family Research Institute.

Sorenson, S. B., Shen, H., \& Kraus, J. F. (1997a). Coroner-reviewed infant and toddler deaths. Many "undetermineds" resemble homicides. Evaluation Review, 21(1), 58-76. 
Sorenson, S. B., Shen, H., \& Kraus, J. F. (1997b). Undetermined manner of death. A comparison with unintentional injury, suicide, and homicide death. Evaluation Review, 21(1), 43-57.

Tulchinsky, T. H., \& Varavikova, E. A. (1996). Addressing the epidemiologic transition in the former Soviet Union: Strategies for health system and public health reform in Russia. American Journal of Public Health, 86(3), 313-320.

Vaysman, D. A., Dubrovina, E. V., \& Redko, A. N. (2006). Information support for studies of mortality in Russia. Obschestvennoe zdorovye i profilaktika zabolevaniy [Public Health and Disease Prevention], 6, 31-38.

Walberg, P., McKee, M., Shkolnikov, V., Chenet, L., \& Leon, D. A. (1998). Economic change, crime, and mortality crisis in Russia: Regional analysis. British Medical Journal, 317(7154), 312-318.

Wasserman, D., \& Varnik, A. (1998). Reliability of statistics on violent death and suicide in the former USSR, 1970-1990. Acta Psychiatrica Scandinavica, 98, 34-41.

WHO. (1992). ICD-10: International statistical classification of diseases and related health problems. World Health Organization. 